\title{
Distributing KI pills to minimize thyroid radiation exposure in case of a nuclear accident in France
}

\author{
Bernard Le Guen, Laurent Stricker and Martin Schlumberger
}

Pressurized water reactors contain fissile iodine products. After an accident, radioactive iodine can therefore be released into the environment and potentially be inhaled or ingested in contaminated food. lodine is concentrated by the thyroid, and low contamination levels can expose the thyroid to significant doses of radiation, while doses to other organs are small. The thyroid gland is one of the most sensitive organs to the carcinogenic effects of ionizing radiation when exposure occurs at a young age, but the risk diminishes with age at exposure.

Approximately $20 \%$ of the iodine products in the reactor core at the Chernobyl nuclear reactor were released into the atmosphere following the accident in 1986. The high rate of subsequent thyroid cancer, especially among contaminated children, demonstrates the need for prophylaxis in case exposure occurs.

The designs of French nuclear reactors are different from that of Chernobyl, and safety systems include rigorous plant operation standards, cladding around the fuel elements, protective barriers, containment systems, and plant monitoring by an independent safety authority. For details of the relevant legislation (in French), see http://www.legifrance.gouv.fr/WAspad/UnT exteDeJorf?numjo=DEVX0100081L (accessed 21 June 2007). Currently under construction, the new Evolutionary Power Reactor will ensure the long-term integrity of the containment in the event of an accident. To complement the protection strategy for the public in the event of a nuclear accident in France, the authorities introduced an extra measure: the distribution of $\mathrm{KI}$ tablets, to be taken early after an accident to prevent radioactive iodine being concentrated by the thyroid. Administration of iodide can reduce the thyroid radiation dose by $98 \%$ if taken before exposure to a radioactive plume, by $90 \%$ if administered at the time of exposure, and by $50 \%$ if taken $6 \mathrm{~h}$ afterwards.

\section{"Administration of iodide can reduce the thyroid radiation dose by $98 \%$..."}

B Le Guen is a medical advisor and L Stricker is an advisor on nuclear issues to the President of Electricité de France Council for Radiation Protection, Saint Denis, France; $M$ Schlumberger is an Advisory Board member of Nature Clinical Practice Endocrinology \& Metabolism.

\footnotetext{
Competing interests The authors have declared associations with the following company: Electricité de France. See the article online for full details of the relationship.

www.nature.com/clinicalpractice doi:10.1038/ncpendmet0593
}

Electricité de France was entrusted with distributing boxes containing $10130 \mathrm{mg} \mathrm{KI}$ tablets to all members of the public residing within a $10 \mathrm{~km}$ radius of its 19 nuclear sites. Stockpiles are also kept, for example in daycare centers, schools and workplaces. Tablets are also distributed to neighboring communities, but anyone in France can obtain them. The tablets are classified as a medicine and are distributed via conventional pharmacies; they should be renewed every 7 years. A 'Biotox' plan has been set up to keep inventories of the tablets.

Three national distribution campaigns have been conducted (Le Guen B et al. [2002] Health Phys 83: 293-300). During the last campaign, individuals in communities close to nuclear facilities received letters inviting them to collect their KI tablets free of charge from pharmacies; the letters also contained explanatory information describing the risks associated with iodide administration, and explaining how nuclear safety was managed locally. Bar codes were used to track compliance, and $\mathrm{KI}$ was thus distributed to more than $60 \%$ of the target population. An additional postal consignment was dispatched to cover the remainder.

The tablets are not recommended for persons aged over 60 years, or for adults suffering from known thyroid or cardiovascular disorders. In the event of an accident, the order to administer tablets to younger people would be given by the relevant authorities if the thyroid dose was forecast to exceed $100 \mathrm{mSv}$. The KI tablet is, however, hard to dissolve in babies' bottles, and an effervescent form is desirable. Some countries use breakable tablets to ease administration and allow accurate dosing for infants and young children. Such improvements, and the effectiveness of the current distribution system, will continue to be monitored to try to provide effective prophylaxis for the public. 